\title{
Investigation and Clinical Importance of Obsessive and Compulsive Signs Among Patients with Restless Legs Syndrome
}

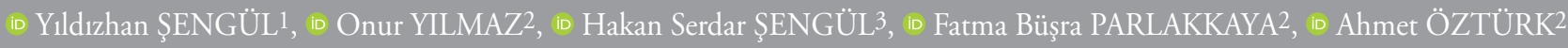

${ }^{1}$ Bezmialem Vakıf University Faculty of Medicine, Department of Neurology, İstanbul, Turkey

${ }^{2}$ Bezmialem Vakıf University Faculty of Medicine, Department of Psychiatry, İstanbul, Turkey

${ }_{3}^{3}$ Gaziosmanpaşa Taksim Training and Research Hospital, Clinic of Psychiatry, İstanbul, Turkey

\begin{abstract}
Objective: The purpose of this study was to examine obsessive and compulsive signs among patients with Restless Legs syndrome (RLS), to compare the results with healthy controls and to investigate clinic importance of those signs.

Methods: Thirty nine patients with RLS and 40 age-, sex- and education- matched healthy controls were assessed in Bezmialem Foundation University Medical Faculty Hospital Neurology and Psychiatry Clinics Hospital. Structured Clinical Interview for Diagnostic and Statistical Manual of Mental Disorders-IV axis-1 disorders severe combined immune deficiency-1, socio-demographic data form and Maudsley obsessive compulsive inventory (MOCI) were applied to both patients and controls. Patient group was also classified according to the International RLS study group RLS severity scale.

Results: Patient group had higher MOCI total scores and doubting and rumination subscale scores than the control group and the difference was statistically significant $(\mathrm{p}<0.05)$. No statistically significant relationship was found between RLS severity score and MOCI total and subscale scores.

Conclusion: Patients with RLS were generally found to have more obsessive and compulsive signs than healthy controls. In view of the fact that RLS is often a late-diagnosed syndrome, searching for concomitant RLS among young people who have obsessive and compulsive signs may be helpful for early diagnosis of RLS.
\end{abstract}

Keywords: Restless legs syndrome, alexithymia, depression, anxiety

\section{Introduction}

Restless Legs syndrome (RLS) is a common neurological syndrome which is sometimes diagnosed incorrectly or with delay and sometimes can not be diagnosed. It is classified in sleeprelated movement disorders. The main symptoms are unpleasant sensations such as tingling and rubbing in the legs. It also presents with insomnia, fatigue, pain and depressive symptoms $(1,2)$. Although the pathophysiology of RLS is not fully understood, it has been reported that it may be associated with disorders in dopamine metabolism $(3,4)$.
The criteria for diagnosis of RLS were determined by the International RLS Study Group (IRLSSG) (1). By the same group, a scale was developed to determine the severity of the disease for use in clinical trials (IRLSSG RLS severity scale) (2). RLS may be idiopathic (primary) or may develop secondary to situations such as iron deficiency anemia, renal failure and pregnancy (5-7).

It is known that psychiatric disorders can also be seen in patients with RLS. Although there are few studies investigating the existence of this comorbidity in the last 20 years, there has been an increase in interest in this area in recent years. The most common

Address for Correspondence: Onur YILMAZ, Bezmialem Vakıf University Faculty of Medicine, Department of Psychiatry, İstanbul, Turkey

Phone: +90 5336580934 E-mail: ony1978@gmail.com ORCID ID: orcid.org/0000 000282707354

Cite this article as: Şengül Y, Yılmaz O, Şengül HS, Parlakkaya FB, Oztürk A. Investigation and Clinical Importance of Obsessive and Compulsive Signs Among Patients with Restless Legs Syndrome. Bezmialem Science 2019;7(3):221-7. 
psychiatric symptoms in patients with RLS are depression and anxiety $(8,9)$. The association of RLS with other psychiatric conditions such as attention deficit and hyperactivity disorder (ADHD) and obsessive compulsive disorder (OCD), which are disorders of dopaminergic and serotonergic neurotransmitter systems, has also been investigated $(10,11)$.

Although iron is an important modulator in neurotransmission, it is not yet clear how the disturbances in iron homeostasis in the brain disrupts neurotransmission and leads to the development of RLS (12). There are literature showing that iron deficiency changes monoaminergic activity in the central nervous system. In another study, repeated blood intake from guinea pigs showed increased levodopa (L-DOPA) levels in the caudat nuclei and in the prefrontal cortex, decreased L-DOPA levels in the anterior horn of the spinal cord, decreased serotonin levels in caudat nucleus, substantia nigra and putamen. In the same study, extracellular monoamine concentrations were measured and there was a significant increase in dopamine and serotonin levels in the striatum and a tendency of increase in leukotomotor activity, which was measured both day and night, as the number of blood intakes was increased (13). In a study, it was suggested that $\mathrm{OCD}$ and $\mathrm{ADHD}$ were included in clinical manifestations of RLS and that comorbid psychiatric conditions such as OCD and ADHD could be occult in patients with RLS, especially with marked iron deficiency anemia (14).

According to the criteria of the diagnostic and statistical manual of mental disorders (DSM-5); repetitive and persistent thoughts, impulses, or images that come to mind involuntarily and by force and that cause marked anxiety or distress in most people, are called obsessions and thinking new ideas or performing certain actions for the purpose of reducing the anxiety of these thoughts are called compulsions $(15,16)$.

Classical knowledge of the disturbance in the monoaminergic transmission in the central nervous system on the ground of obsessions and compulsions is more focused on serotonin and dopamine. In patients with OCD, there is an increase in 5-hydroxyindoleacetic acid (5-HIAA) level, which is a serotonin metabolite, in cerebrospinal fluid (CSF). OCD responds significantly to treatment with clomipramine, a tricyclic antidepressant. A significant decrease in the level of 5-HIAA in CSF in patients with OCD treated with clomipramine was reported in a study (17). It is known that a positive correlation is found between the response level to clomipramine and serum concentration of clomipramine. However, no such correlation is found with desmetylclomipramine, an active metabolite of clomipramine preventing noradrenergic uptake. These data support that serotonin may be considered more important than noradrenaline in the etiology of OCD (18).

It is known that combination of low-dose antipsychotic drugs with selective serotonin reuptake inhibitors increases treatment response in OCD. This may be considered as a clinical evidence demonstrating the importance of dopamine in the etiology of OCD. It has been reported that the balance between dopaminergic and serotonergic activities in the central nervous system is also found on the background of some types of OCD (19). These data show that the disturbances in serotonergic mechanism as well as in the dopaminergic mechanism are also involved in the etiology of OCD.

There are a small number of studies in the literature referring to the relationship between obsessive compulsive symptoms and RLS. In a study comparing healthy volunteers with patients with RLS by using software collection (SCL)-90, the scores of, especially, somatization and obsessive compulsive subscales in patients with RLS were found to be significantly higher than healthy volunteers (20). In another study comparing healthy volunteers with patients with RLS, SCL-90 test was used. In untreated patients with RLS, especially somatization, compulsivity, anxiety and depression subscale scores were higher, while in treated patients with RLS, difference in terms of somatization subscale score disappeared, but still compulsivity depression and anxiety subscale scores were higher in treated patients with RLS (21).

In this study, we aimed to investigate obsessive-compulsive symptoms in patients with RLS and compare them with healthy volunteers. In addition to the previously reported relationship between RLS and obsessive compulsive symptoms and psychosomatic diseases, we aimed to examine this relationship in more detail as disturbances in the activity of serotonergic, dopaminergic and other neurotransmitter systems are proposed for obsessions and compulsions in the etiopathogenesis of RLS.

\section{Methods}

Our study was carried out in Bezmialem Vakıf University Faculty of Medicine Psychiatry and Neurology Services. Study protocol was approved by the Bezmialem Vakıf University Ethics Committee of non-invasive studies. Bezmialem Vakıf University was approved by the Ethics Committee of non-interventional studies in an acceptable condition $(19.08 .2017,16 / 3)$.

\section{Participants}

Thirty nine patients diagnosed as having RLS according to the diagnosis criteria of the IRLSSG and, age, education and gendermatched forty healthy control subjects were included in the study. All subjects were 18 years of age or older. Patients with RLS symptoms due to comorbid conditions such as pregnancy, kidney failure, endocrine disorders, subjects with alcohol and substance use disorder, and with active major psychiatric disorders such as major depressive disorder, bipolar disorder and schizophrenia and were excluded from the study. By making necessary explanations about the study, all volunteers who agreed to participate in the study signed informed consent forms.

\section{Measurement Tools}

Patients diagnosed as having RLS and control subjects underwent Turkish forms of the Structured Clinical Interview for the DSMIV Axis I Disorders (SCID-1), the socio-demographic data form and the Maudsley Obsessive Compulsive Inventory. In addition, the patient group underwent the RLS severity scale created by the IRLSSG. 
The Structured Clinical Interview for the DSM-IV Axis I Disorders (SCID-1): It is a structured clinical interview formed by First et al. (22) for DSM-IV axis I disorders. Validity and reliability of its Turkish form was made by Özkürkçügil et al. (23).

IRLSSG RLS Severity Scale: This scale developed by the IRLSSG is a 10-question self-declaration measure, which is rated by $0-4$ points according to the severity of the typical and common symptoms of the disease within the last 1 week before the test date. A total score between 0-10 suggests mild RLS, between 11-20 moderate, between 21-30 severe and between 31-40 very severe RLS (2).

The Maudsley Obsessive Compulsive Inventory (MOCI): It is used to measure the type and severity of obsessive compulsive symptoms. It is a self-declaration scale developed by Hodgson and Rachman (24). As the scale scores increase, it is assumed that the severity of obsessive compulsive symptoms increases. The adaptation of the scale to Turkish, as well as the validity and reliability of the Turkish form were done by Erol and Savasir (25). The scale can be applied to healthy subjects and psychiatric patients. The original scale is consisted of 30 items and contains 4 sub-scales which are called checking, cleaning, slowness and doubting sub-scales. Seven items from Minnesota Multiple Personality Inventory (MMPI) and one sub-scale called rumination are added to the Turkish form of Maudsley obsessive compulsive inventory (MOCI) and as a result it contains 37 items and 5 sub-scales. Measurement is done based on "true" or "wrong" responses that participants give.

\section{Statistical Analysis}

Statistical analysis of the data of our study which was planned as a cross-sectional study, was performed using SPSS 24.0 package program. All numerical variables were expressed as mean \pm standard deviation, and categorical variables were represented by frequency and probability tables.

Kolmogorov Smirnov and Shapiro-Wilk tests were performed to test the compatibility of the sample with normal distribution in terms of age and educational level. It was shown that it had normal distribution.

Due to the compatibility with the normal distribution, independent samples t-test (Student t-test) was used for comparison of numerical data and the chi-square test was used for comparison of categorical variables. Pearson correlation test was applied to investigate the correlation between numerical data. A p value $<0.05$ was accepted as statistically significant in all statistical analyses.

\section{Results}

The study was planned to be completed with forty-four patients but it completed with 39 patients. One patient was excluded due to being feeble-mindedness, one due to having chronic renal failure, one due to having iron deficiency anemia, two due to meeting the criteria of having a major psychiatric disorder (major depressive disorder in one and alcohol abuse in another) after performing SCID-1, although they reached testing phase. The control group was composed of 40 healthy volunteers involving the staff of Bezmialem Vakıf University Center and their families. The mean age of the patients and control group was $43.4 \pm 8.5$ years and $39.7 \pm 11.7$ years, respectively, and no significant differences were found between them. There was no significant difference between the groups in terms of the marital status and educational level (Table 1).

Patient and control groups were compared in terms of MOCI total score and 5 sub-scale mean score. Total MOCI score and mean scores of doubting and rumination sub-scales were significantly higher in the patient group compared with the control group $(\mathrm{p}<0.05)$. Similarly, mean scores of checking, cleaning and slowness sub-scales were higher in the patient group compared with the control group, without reaching statistical significance (Table 2).

Table 1. Comparison of sociodemographic data of the patient and control groups

\begin{tabular}{|c|c|c|c|}
\hline & $\begin{array}{l}\text { Patient group } \\
(n=39)\end{array}$ & $\begin{array}{l}\text { Control group } \\
(n=40)\end{array}$ & $p$ \\
\hline Age & $43.4 \pm 8.5$ & $39.7 \pm 11.7$ & 0.11 \\
\hline \multicolumn{4}{|l|}{ Gender } \\
\hline $\begin{array}{l}\text { Female } \\
\text { Male }\end{array}$ & $\begin{array}{l}29(74.4 \%) \\
10(25.0 \%)\end{array}$ & $\begin{array}{l}28(70.0 \%) \\
12(30.0 \%)\end{array}$ & 0.67 \\
\hline \multicolumn{4}{|l|}{ Marital status } \\
\hline $\begin{array}{l}\text { Married } \\
\text { Single } \\
\text { Divorced. widow }\end{array}$ & $\begin{array}{l}28(71.8 \%) \\
8(20.5 \%) \\
3(7.7 \%)\end{array}$ & $\begin{array}{l}23(57.5 \%) \\
14(35.0 \%) \\
3(7.5 \%)\end{array}$ & 0.35 \\
\hline \multicolumn{4}{|l|}{ Education } \\
\hline $\begin{array}{l}\text { Literate } \\
\text { Primary school } \\
\text { Secondary school } \\
\text { Undergraduate } \\
\text { Postgraduate }\end{array}$ & $\begin{array}{l}1(2.6 \%) \\
17(43.6 \%) \\
7(17.9 \%) \\
3(7.7 \%) \\
11(28.2 \%)\end{array}$ & $\begin{array}{l}2(5.0 \%) \\
1025.0 \%) \\
9(22.5 \%) \\
8(20.0 \%) \\
11(27.5 \%)\end{array}$ & 0.32 \\
\hline$n=$ Sample size, $p=p$ & & & \\
\hline
\end{tabular}

Table 2. Total and sub-scale scores of $\mathrm{MOCl}$ of the patient and control groups

\begin{tabular}{|l|l|l|l|}
\hline & $\begin{array}{c}\text { Patient } \\
(\mathrm{n}=39)\end{array}$ & $\begin{array}{c}\text { Control } \\
(\mathrm{n}=40)\end{array}$ & $\mathrm{p}$ \\
\hline Checking & $2.4 \pm 2.5$ & $1.6 \pm 1.8$ & 0.097 \\
\hline Cleaning & $4.0 \pm 2.4$ & $3.0 \pm 2.4$ & 0.079 \\
\hline Slowness & $1.9 \pm 1.5$ & $1.4 \pm 1.3$ & 0.175 \\
\hline Doubting & $3.3 \pm 1.5$ & $2.4 \pm 1.7$ & 0.013 \\
\hline Rumination & $1.9 \pm 1.3$ & $1.2 \pm 1.1$ & 0.011 \\
\hline Moci total & $13.4 \pm 7.0$ & $9.4 \pm 6.2$ & 0.008 \\
\hline
\end{tabular}

$\mathrm{n}=$ Sample size, $\mathrm{p}=\mathrm{p}$ value, Checking= Mean score of checking sub-scale, Cleaning: Mean score of cleaning sub-scale, Slowness= Mean score of slowness sub-scale, Doubting= Mean score of doubting sub-scale, Rumination= Mean score of rumination sub-scale, MOCl-total: Mean of total score of the Maudsley Obsessive Compulsive Inventory 
Table 3. Correlation values of RLS severity and MOCI total and sub-scale scores in terms of $p$ value in the patient group

\begin{tabular}{|c|c|c|c|c|c|c|c|}
\hline & RLS severity & Checking & Cleaning & Slowness & Doubting & Rumination & MOCI-Total \\
\hline Checking & 0.810 & & $0.01^{*}$ & $<0.01^{*}$ & $<0.01$ * & 0.07 & $<0.01^{*}$ \\
\hline Slowness & 0.460 & $<0.01 *$ & $0.013^{*}$ & & $<0.01$ * & 0.050 & $<0.01^{*}$ \\
\hline Doubting & 0.479 & $<0.01 *$ & $0.036^{*}$ & $<0.01 *$ & & $0.01 *$ & $<0.01$ * \\
\hline MOCI-Total & 0.500 & $<0.01^{*}$ & $<0.01 *$ & $<0.01^{*}$ & $<0.01 *$ & $<0.01$ * & \\
\hline \multicolumn{8}{|c|}{$\begin{array}{l}\text { RLS severity: Mean of total score of restless legs syndrome severity, Checking: Mean score of checking sub-scale, Cleaning: Mean score of cleaning sub-scale } \\
\text { Slowness: Mean score of slowness sub-scale, Doubting: Mean score of doubting sub-scale, Rumination: Mean score of rumination sub-scale, MOCI-total: Mean o } \\
\text { total score of the Maudsley Obsessive Compulsive Inventory } \\
\text { Note: Significant correlations were identified with the * sign }\end{array}$} \\
\hline
\end{tabular}

There was no statistically significant relationship between RLS severity score and MOCI total and sub-scale scores in the patient group (Table 3). There was positive correlation between mean MOCI total score and all sub-scale scores. MOCI sub-scale scores were found to be correlated with each other except rumination sub-scale. No relation was found between rumination sub-scale and checking, cleaning and slowness sub-scales. Only doubting sub-scale was found to be positively correlated with rumination sub-scale.

\section{Discussion}

The main result of our study was that obsessive compulsive symptoms were found more in patients with RLS than in healthy volunteers.

There may be delay in diagnosis of RLS in some cases. Because most of the patients with RLS have difficulty in recognizing and expressing sensory symptoms. Pain which can be easily understood and expressed, is found in about half of the patients with RLS, and is particularly noticeable in aircraft, cinema and similar environments where patients' movements are restricted (26). Since early recognition of RLS and early initiation of treatment will significantly increase the success of treatment, it may be helpful to investigate the possible diagnosis of RLS that accompanies comorbid conditions other than sensory symptoms.

The first study to investigate the comorbidity of psychiatric disorders in patients with RLS was published in 1965. In that study, the MMPI was applied to a group of patients who were admitted to the hospital. Depression and psychasthenia scores in the MMPI were found to be higher in patients with RLS than general patient population and than those who were admitted to psychiatry and (27). Psychiatric comorbidity in RLS has become more interesting especially in the last twenty years. In a study, RLS was shown to be associated with major depressive disorder and panic disorder (28). In another study, it was found that psychiatric disorders, such as major depressive disorder, panic disorder, post-traumatic stress disorder, were associated with RLS according to the DSM-IV criteria (29).
Besides dopaminergic mechanism, glutamaterjic (30), serotoninergic (31) and opioid (32) neurotransmitter mechanisms have also been proposed in the etiology of RLS. Although in obsessions and compulsions, serotonergic and dopaminergic neurotransmitter mechanisms are generally focused on, research is ongoing on other neurotransmitter systems, especially due to high treatment-resistant patients. Various studies have been conducted in OCD examining the disturbances of glutamatergic system (33). A study reported that drugs that are effective over glutamatergic system might be useful in the augmentation treatment of OCD (34). In a recent study published in our country, it was noted that n-methyl $\mathrm{d}$-aspartic acid receptor modulators were effective in rapid treatment of OCD (35).

Reports have been made on the role of opioid system in OCD (36). In a recent study, it was shown that opioid system might play a common role in pathophysiology and treatment of OCD, impulse control disorders and drug addiction and that drugs effecting opioid receptors such as naltrexone and buprenorphine might be effective in some of OCD forms (37).

Although RLS is a neurological syndrome, psychosomatic symptoms often accompany this picture (38). It is also shown that psychosomatic symptoms accompanies OCD. In one study, it was found that body dysmorphic disorder was relatively common in patients with OCD (39). The relationship between OCD and different psychosomatic diseases is remarkable. In particular, there are numerous reports that OCD spectrum disorders are associated with dermatological diseases of psychosomatic origin $(40,41)$.

There are associations in the neurotransmitter mechanisms of RLS and OCD, as well as psychiatric conditions such as impulse control disorders, psychosomatic disorders, depression and anxiety disorders that can accompany both RLS and OCD.

Based on these data, we can explain the frequent occurrence of obsessive compulsive symptoms in patients with RLS in our study for the following reasons: 
a) Dysfunctions in serotonine, dopamine and other neurotransmitter systems accompany both RLS and OCD.

b) Both RLS and OCD are frequently associated with psychosomatic disorders.

c) Both RLS and OCD are frequently associated with depression and anxiety.

There are studies indicating that as age progresses, cortical dopamine D2 receptor density decreases (42). As a result of our partial correlation analysis, it was found that the relationship between OCD and RLS was not affected by age. Studies indicate that cortical D2 receptor density varies according to gender (43). Although the number of male patients was significantly lower than the number of female patients in our study, partial correlation analysis showed that the relationship between OCD and RLS was not affected by gender.

There was no significant correlation between RLS severity and MOCI scores in patients. We can link this finding to the excess number of factors affecting both RLS and OCD severity, the presence of roles of other neurotransmitters other than dopamine in both disorders, and the diversity of sub-types reported to be present in both disorders.

One limitation of our study was that the number of male patients $(n=10,25.6 \%)$ was significantly lower than the number of female patients ( $n=29,74.4 \%)$. The number of females who are diagnosed as having RLS is higher than the number of males who are diagnosed as having RLS, which may be a reason for this. However, by doing partial correlation analysis, we found that the relationship between RLS and OCD was not affected by gender. Another limitation was that; we could not directly explain why the mean score of rumination sub-scale was not correlated with the mean score of sub-scales other than doubting subscale, while the mean scores of MOCI sub-scales other than rumination subscale were positively correlated with each other. Since rumination and doubting can also be seen in other psychiatric disorders other than OCD such as major depression and paranoid disorders, their correlation with each other as OCD sub-scales and lack of correlation between them and other sub-scales are expected. These data may indicate that the rumination sub-scale, which is not found in the original scale, but is added to the Turkish form during the validity and reliability study, needs further studies in our country. Another limitation of our study was that patients with impulse control disorders or with major psychiatric disorders, such as alcohol and substance abuse disorders were not included in the study. As the presence of these disorders might be a confusing factor in testing our main hypothesis, we excluded them.

\section{Conclusion}

But this situation eliminated the possibility of associating the obsessive and compulsive symptoms with impulsive features in patients with RLS and the possibility of differentiating them into subtypes accordingly. In addition, we did not have a chance to determine whether accompanying psychiatric disorders had an impact on OCD symptoms in patients with severity and course of RLS.

As a result, we suggest that the relationship between obsessive compulsive symptoms and RLS should be investigated by further studies searching neurotransmitter mechanisms, especially dopamine and serotonin, accompanied by neuroimaging methods which may also be associated with obsessive compulsive symptoms in young patients. In addition, we suggest that bringing RLS to mind that may accompany young patients with obsessive compulsive symptoms may help increase the early diagnosis of RLS.

\section{Ethics}

Ethics Committee Approval: Bezmialem Vakif University was approved by the Ethics Committee of non-interventional studies in an acceptable condition $(19.08 .2017,16 / 3)$.

Informed Consent: Taken from the patient.

Peer-review: Externally and internally peer-reviewed.

\section{Authorship Contributions}

Consept: Y.Ş., O.Y., Design: H.S.Ş., F.B.P., Data Collection or Processing: Y.Ş., O.Y., F.B.P., Analysis or Interpretation: Y.Ş., O.Y., A.Ö., Literature Search: Y.Ş., O.Y., F.B.P., Writing: D.Y., A.Ö.

Conflict of Interest: No conflict of interest was declared by the authors.

Financial Disclosure: The authors declared that this study received no financial support.

\section{References}

1. Allen RP, Picchietti D, Hening WA, Trenkwalder C, Walters AS, Montplaisi J, et al. Restless legs syndrome: diagnostic criteria, special considerations, and epidemiology. A report from the restless legs syndrome diagnosis and epidemiology workshop at the National Institutes of Health. Sleep Med 2003;4:101-19.

2. Horiguchi J, Hornyak M, Voderholzer U, Kryger M, Skomrow R, Lipinski JF, et al. Validation of the International Restless Legs Syndrome Study Group rating scale for restless legs syndrome. Sleep Med 2003;4:121-32.

3. Cervenka S, Pålhagen SE, Comley RA, Panagiotidis G, Cselényi Z, Matthews JC, et al. Support for dopaminergic hypoactivity in restless legs syndrome: a PET study on D2-receptor binding. Brain 2006; 129:2017-28.

4. Connor JR, Wang X-S, Allen RP, Beard JL, Wiesinger JA, Felt BT, et al. Altered dopaminergic profile in the putamen and substantia nigra in restless leg syndrome. Brain 2009;132:2403-12.

5. Allen RP, Auerbach S, Bahrain H, Auerbach M, Earley C. The prevalence and impact of restless legs syndrome on patients with iron deficiency anemia. Am J Hematol 2013;88:261-4.

6. Merlino G, Lorenzut S, Gigli GL, Romano G, Montanaro D, Moro A. et al. A case-control study on restless legs syndrome in nondialyzed patients with chronic renal failure. Mov Disord. 2010;25:1019-25. 
7. Manconi M, Govoni V, De Vito A, Economou NT, Cesnik E, Mollica $\mathrm{G}$ et al. Pregnancy as a risk factor for restless legs syndrome. Sleep Med 2004;5:305-8.

8. Trenkwalder C, Paulus W, Walters AS. The restless legs syndrome. Lancet Neurol 2005;4:465-75.

9. Sevim S, Doğu O, Kaleağası H, Aral M, Metin O, Çamdeviren H. Correlation of anxiety and depression symptoms in patients with restless legs syndrome: a population based survey. J Neurol Neurosurg Psychiatry 2004;75:226-30.

10. Solanto MV. Neuropsychopharmacological mechanisms of stimulant drug action in attention-deficit hyperactivity disorder: a review and integration. Behav Brain Res 1998;94:127-52.

11. Stein DJ. Neurobiology of the obsessive-compulsive spectrum disorders. Biol Psychiatry 2000;47:296-304.

12. Earley CJ, Connor J, Garcia-Borreguero D, Jenner P, Winkelman $\mathrm{J}$, Zee PC, et al. Altered brain iron homeostasis and dopaminergic function in Restless Legs Syndrome (Willis-Ekbom Disease). Sleep Med 2014;15:1288-301.

13. Hyacinthe C, De Deurwaerdere P, Thiollier T, Li Q, Bezard E, Ghorayeb I. Blood withdrawal affects iron store dynamics in primates with consequences on monoaminergic system function. Neuroscience 2015;290:621-35.

14. Ghorayeb I, Gamas A, Mazurie Z, Mayo W. Attention-Deficit Hyperactivity and Obsessive-Compulsive Symptoms in Adult Patients With Primary Restless Legs Syndrome: Different Phenotypes of the Same Disease? Behav Sleep Med 2017;17:1-8.

15. American Psychiatric Association, American Psychiatric Association. DSM-5 Task Force. Diagnostic and statistical manual of mental disorders: DSM-5. American Psychiatric Association; 2013. p 947.

16. Van Ameringen M, Patterson B, Simpson W. DSM-5 obsessivecompulsive and related disorders: clinical implications of new criteria. Depress Anxiety 2014;31:487-93.

17. Altemus M, Swedo SE, Leonard HL, Richter D, Rubinow DR, Potter WZ, et al. Changes in cerebrospinal fluid neurochemistry during treatment of obsessive-compulsive disorder with clomipramine. Arch Gen Psychiatry 1994;51:794-803.

18. Kelly MW, Myers CW. Clomipramine: A tricyclic antidepressant effective in obsessive compulsive disorder. DICP 1990;24:739-44.

19. Goodman WK, McDougle CJ, Price LH, Riddle MA, Pauls DL, Leckman JF. Beyond the serotonin hypothesis: A role for dopamine in some forms of obsessive compulsive disorder? J Clin Psychiatry 1990;51:36-43.

20. Kim J Bin, Koo YS, Eun M-Y, Park K-W, Jung K-Y. Psychosomatic symptom profiles in patients with restless legs syndrome. Sleep Breath 2013;17:1055-61.

21. Scholz H, Benes H, Happe S, Bengel J, Kohnen R, Hornyak M. Psychological distress of patients suffering from restless legs syndrome: a cross-sectional study. Health and quality of life outcomes 2011;9:73.

22. First MB, Spitzer R, Giboobn M, Williams J. Structed Clinical Interview for DSM IV Axis Disorders (SCID-1) Clinical Version.
Washington DC and London: American Psychiatric Press;1997.

23. Özkürkçügil A, Aydemir Ö, Yılmaz M, Esen Danacı A, Köroğlu E. DSM-IV Eksen I bozuklukları için yapılandırılmış klinik görüşmenin Türkçeye uyarlanması ve güvenilirlik çalışması. İlaç ve Tedavi Derg 1999;12:233-6.

24. Hodgson RJ, Rachman S. Obsessional-compulsive complaints. Behav Res Ther 1977;15:389-95.

25. Erol N, Savaşır I. Maudsley Obsessif-Kompulsif Soru Listesinin Türkiye Uyarlaması. In: XXIV Ulusal Psikiyatri ve Nörolojik Bilimler Kongresi Bildiri Kitabı. Ankara: Gata Basımevi: 1988.p.107-14.

26. Merlino G, Valente M, Serafini A, Gigli GL. Restless legs syndrome: diagnosis, epidemiology, classification and consequences. Neurol Sci 2007;28:37-46.

27. Gorman CA, Dyck PJ, Pearson JS. Symptom of Restless Legs. Arch Intern Med 1965;115:155-60.

28. Lee HB, Hening WA, Allen RP, Kalaydjian AE, Earley CJ, Eaton WW, et al. Restless Legs Syndrome is Associated with DSM-IV Major Depressive Disorder and Panic Disorder in the Community. J Neuropsychiatry Clin Neurosci 2008;20:101-5.

29. Cho S-J, Hong JP, Hahm B-J, Jeon HJ, Chang SM, Cho MJ, et al. Restless Legs Syndrome in a Community Sample of Korean Adults: Prevalence, Impact on Quality of Life, and Association with DSM-IV Psychiatric Disorders. Sleep 2009;32:1069-76.

30. Allen RP, Barker PB, Horská A, Earley CJ. Thalamic glutamate/ glutamine in restless legs syndrome: increased and related to disturbed sleep. Neurology 2013;80:2028-34.

31. Jhoo JH, Yoon I., Kim YK, Chung S, Kim JM, Lee SB, et al. Availability of brain serotonin transporters in patients with restless legs syndrome. Neurology 2010;74:513-8.

32. Walters AS, Ondo WG, Zhu W, Le W. Does the endogenous opiate system play a role in the Restless Legs Syndrome? A pilot postmortem study. J Neurol Sci 2009;279:62-5.

33. Pittenger C, Bloch MH, Williams K. Glutamate abnormalities in obsessive compulsive disorder: Neurobiology, pathophysiology, and treatment. Pharmacol Ther 2011;132:314-32.

34. Marinova Z, Chuang D-M, Fineberg N. Glutamate-Modulating Drugs as a Potential Therapeutic Strategy in Obsessive-Compulsive Disorder. Curr Neuropharmacol 2017;15:977-95.

35. Köse S, Çetin M. Ketamine and rapastinel: NMDA receptor modulators in the rapid treatment of obsessive compulsive disorder. Psychiatry Clin Psychopharmacol 2017;27:213-4.

36. Urraca N, Camarena B, Gómez-Caudillo L, Esmer MC, Nicolini H. $\mu$ opioid receptor gene as a candidate for the study of obsessive compulsive disorder with and without tics. Am J Med Genet Part B Neuropsychiatr Genet 2004;127:94-6.

37. Fontenelle LF, Oostermeijer S, Harrison BJ, Pantelis C, Yücel M. Obsessive-compulsive disorder, impulse control disorders and drug addiction. Drugs 2011;71:827-40.

38. Kim JB, Koo YS, Eun MY, Park KW, Jung KY. Psychosomatic symptom profiles in patients with restless legs syndrome. Sleep Breath 2013; 17:1055-61. 
39. Phillips KA, Gunderson CG, Mallya G, McElroy SL, Carter W. A comparison study of body dysmorphic disorder and obsessivecompulsive disorder. J Clin Psychiatry 1998;59:568-75.

40. Folks DG, Warnock JK. Psychocutaneous disorders. Curr Psychiatry Rep 2001;3:219-25.

41. Zhu TH, Nakamura M, Farahnik B, Abrouk M, Reichenberg J, Bhutani T, et al. Obsessive-compulsive skin disorders: a novel classification based on degree of insight. J Dermatolog Treat
2017;28:342-6.

42. Kaasinen V, Vilkman H, Hietala J, Någren K, Helenius H, Olsson $\mathrm{H}$, et al. Age-related dopamine D2/D3 receptor loss in extrastriatal regions of the human brain. Neurobiol Aging 2000;21:683-8.

43. Kaasinen V, Någren K, Hietala J, Farde L, Rinne JO. Sex Differences in Extrastriatal Dopamine D 2 -Like Receptors in the Human Brain. Am J Psychiatry 2001;158:308-11. 